\title{
Desalination of Seawater for Agricultural Irrigation
}

\author{
Victoriano Martinez-Alvarez ${ }^{1, *} \mathbb{(}$, Asher Bar-Tal ${ }^{2}{ }^{-}$, Francisco Javier Diaz Peña ${ }^{3}$ and \\ Jose F. Maestre-Valero ${ }^{1}$ \\ 1 Agricultural Engineering Center, Technical University of Cartagena, Paseo Alfonso XIII 48, \\ 30203 Cartagena, Spain; josef.maestre@upct.es \\ 2 Agricultural Research Organization, The Volcani Center, POB 15159, Rishon LeZion 750510, Israel; \\ abartal@volcani.agri.gov.il \\ 3 Department of Animal Biology, Soil Science and Geology, University of La Laguna, \\ 38206 La Laguna, Canary Islands, Spain; fjdiazpe@ull.es \\ * Correspondence: victoriano.martinez@upct.es
}

Received: 5 June 2020; Accepted: 13 June 2020; Published: 16 June 2020

\begin{abstract}
Food security concerns, climate change impacts, and increased pressure on conventional water resources have encouraged the agricultural use of nonconventional water resources in the last decade. As a result, desalinated seawater (DSW) has already consolidated its position as an alternative source to increase the supply for crop irrigation in Spain and Israel, where farmers' acceptance is progressively on the rise. The first experiences in these regions highlighted that DSW agricultural use involves new agronomic, economic, and environmental challenges which require innovative research approaches and imply novel water management strategies. In this Special Issue, eight high-quality papers which present current research trials and study cases, covering a wide range of topics that are relevant when irrigating with DSW, have been selected. The papers came from the three regions of the world that currently have a massive agricultural DSW supply: Southeastern Spain, Israel, and the Canary Islands.
\end{abstract}

Keywords: desalinated seawater; irrigation water quality; fertilization; water blending; boron phytotoxicity; water cost and price; water-energy nexus

\section{Introduction}

The development of irrigated agriculture, in response to the growing demand for food, is the main driver of the water demand increase in Mediterranean countries. In such regions, the pressure on water resources is becoming more severe, leading to imbalances between renewable resources and total demands. Climate change prospects for Mediterranean countries additionally suggest that the situation is likely to worsen in the future. Innovative initiatives to promote the resilience of irrigated agriculture to the progressive depletion of natural hydrological systems are required, which has fostered the use of desalinated seawater (DSW) for agriculture.

In such a way, large-scale supply with DSW has emerged in the last decade as an alternative water source for sustaining agricultural production in some Mediterranean coastal regions facing persistent water scarcity and growing high-return crops, as well as in islands lacking fresh water resources. DSW represents a steady water source that effectively removes climatological and hydrological constraints. Consequently, its adoption is increasingly being considered as an alternative water supply for crop irrigation, and this trend is expected to intensify in the near future. However, some certain limiting factors that could become barriers to the spread of DSW for crop irrigation [1], such as the high production and allocation energy requirements, the associated greenhouse gas emissions, and the impact of the high cost of DSW on the farming economy, must be considered. Moreover, some other agronomic concerns [2], such as the low nutrient concentration of DSW and the consequent increase 
in the fertigation cost, the risk of crop toxicity due to the high boron (B) concentration, and cation and anion imbalances, or the sodicity risk affecting soil's physical properties, may be added to the drawbacks pool. Therefore, a great deal of experience and further research are still required to promote reliable, sustainable, and profitable agricultural DSW use.

In this context, this Special Issue of Water is devoted to the research opportunities that this new agricultural irrigation source affords. The selected articles cover a wide range of issues that are relevant for improving and encouraging the agricultural use of DSW, including irrigation experiences, advance challenges, and new perspectives on this topic. Below are presented the articles that make up the Special Issue, which are organized by their geographical location.

\section{Summary of the Papers}

\subsection{Southeastern Spain}

Within the agricultural use of DSW in the context of Southeastern Spain, the four manuscripts selected address issues such as (i) the characterization of the use of DSW for irrigation in that region; (ii) the evaluation of the short-term agronomic effects of the irrigation of citrus with DSW; (iii) the analysis of the effect of the use of DSW on the quality of tomatoes produced under soil and soilless systems; and (iv) the evaluation of the perception of both desalination plant managers and irrigation communities with respect to DSW management.

In the paper by Martínez-Alvarez et al. (2019) [3], key questions, such as the role of DSW in regional water planning, the infrastructure needed for its conveyance and distribution, the energy requirements, the production and distribution costs, and the final price to farmers, are evaluated. These researchers base their analysis on descriptive and quantitative data collected from a representative group of desalination plants and irrigation district managers through technical questionnaires and personal interviews. The study concludes that seawater desalination is effectively alleviating the regional constraints in the irrigated agriculture supply, hence becoming a clear strategy to maintain food production and socioeconomic development in the area. However, they also identify the high energy requirements and the associated costs as the main barriers to increased use of DSW.

Concerning the analysis of the agronomic effects of irrigation with DSW on crops, two manuscripts have been included. Maestre-Valero et al. (2020) [4] evaluated the short-term agronomic and economic effects of irrigating a mandarin orchard with DSW during two crop cycles. They analyzed the vegetative growth; the leaf water relations; the leaf concentration of $\mathrm{Na}, \mathrm{Cl}$, and $\mathrm{B}$; the gas exchange parameters; the yield; and the fruit quality. Results were compared to trees irrigated with fresh water and with a mix of water composed of 50\% fresh water and 50\% DSW. Results showed large standard deviations and, hence, statistically significant effects of irrigating with DSW were not observed between treatments. This circumstance was attributed to the youth of the trees and the authors recommend further research considering the effects on adult trees in the long term. Antolinos et al. (2020) [5] studied the effect of irrigating two varieties of tomato, cropped under soil and soilless systems, with DSW on the fruit quality. They used DSW and two well waters to irrigate the tomatoes. A complete fruit quality evaluation, which included the analysis of dry matter content, soluble solids, $\mathrm{pH}$, titratable acidity, firmness, color, and nutritional and bioactive quality, was performed. The study found that irrigation with DSW did not compromise the consumer acceptance or the tomato quality.

Ricart et al. (2020) [6] evaluated how desalination plant managers and irrigation communities interact to address water scarcity. Data for the study were collected from specific questionnaires applied to three desalination plant managers and eleven irrigation communities that used DSW. The study highlighted that (i) irrigation communities considered DSW as a complementary source; (ii) both desalination plant managers and irrigation communities foregrounded the security/guarantee of DSW supply and water quality parameters; and (iii) plant managers and irrigation communities disagreed on the desalination model of seawater provision and management, since irrigators considered that they should be all centralized at regional irrigation associations. The manuscript also identifies that 
water price and energy consumption, lack of water storage capacity, and regulation and environmental impacts are the main barriers to DSW spreading.

\subsection{Israel}

Russo and Kurtzman (2019) [7] explored the downward transport of chloride and nitrate under cropped conditions irrigated with DSW, fresh water, and salinized water, in which the concentrations of chloride were 50, 300, and $640 \mathrm{mg} \mathrm{L}^{-1}$, respectively. The investigation relied on three-dimensional (3-D) simulations of flow and transport in a variably saturated and spatially heterogeneous flow domain performed for three successive years. The model includes the following chloride-nitrate interactions: (i) competition of chloride and nitrate in the uptake by plants; and (ii) reduction in the rate of nitrification with increasing chloride concentration. They showed that the use of low-salinity desalinated water for irrigation may substantially decrease the mass fluxes of both chloride (as expected) and nitrate leached below the root zone. The $\mathrm{N}$ uptake by the plant roots and the mass of nitrate added to the flow system by nitrification increased as the chloride concentration of the water decreased. However, the effect of the chloride-nitrate interactions on the mass fluxes of nitrate downward leaching below the root zone was relatively small.

Bar-Tal et al. (2020) [8] investigated the possibility of reducing the recommended nitrogen fertilization for plants irrigated with DSW in comparison to water with a wide range of chloride concentrations. The yields of the two studied crops, lettuce and potato, in a lysimeter system increased with $\mathrm{N}$ up to optimal $\mathrm{C}_{\mathrm{N}}\left(\mathrm{N}\right.$ concentration of the irrigating solution) and decreased as $\mathrm{C}_{\mathrm{CL}}$ ( $\mathrm{Cl}$ concentration of the irrigating solution) increased. Optimal $\mathrm{C}_{\mathrm{N}}$ in both crops were higher in the DSW than high $\mathrm{C}_{\mathrm{CL}}$ treatments. As expected, $\mathrm{N}$ fertilization suppressed $\mathrm{Cl}$ accumulation in plant tissues, but $\mathrm{N}$ accumulation in plant tissues was not affected by $\mathrm{C}_{\mathrm{CL}}$. DSW enhanced transpiration and reduced the water's leaching fraction. Drainage of $\mathrm{N}$ and $\mathrm{Cl}$ increased with an increase in $\mathrm{C}_{\mathrm{CL}}$ in the irrigating solution and $\mathrm{N}$ fertilization above the optimal $\mathrm{C}_{\mathrm{N}}$ resulted in a steep rise in downward $\mathrm{N}$ leaching. The overall conclusion was that as the water quality is improved through desalination, a higher $\mathrm{N}$ supply is required for high yields with less groundwater pollution by the downward leaching of $\mathrm{N}$ and $\mathrm{Cl}$.

\subsection{The Canary Islands (Spain)}

Monterrey-Viña et al. (2020) [9] assessed the agricultural use of DSW in the southeast region of Gran Canaria Island, an arid territory where crop production depends significantly on non-conventional water resources. A methodology based on geographic information systems, the development of surveying to farmers, and the compilation and analysis of DSW quality data allowed the authors to provide qualitative and quantitative information about the potential benefits and limitations of DSW irrigation in this insular environment. The authors confirm high farmers' acceptance of DSW irrigation, where about $31 \%$ of the agricultural surface in the study area was irrigated with this water quality. The higher price of DSW with regard to other water qualities (i.e., reclaimed wastewater) is likely to be the main limitation for its greater expansion. The use of wind energy to power desalination plants appears to be a potential solution for reducing the production cost of DSW. The authors point out that the sustainability of the system also requires the correction of several water quality problems, mainly focused on improving DSW quality through desalination techniques to reduce boron (B) levels and on the remineralization processes to balance cation concentrations and increase $\mathrm{pH}$ and alkalinity. The research also highlights that farmers' blending strategies by combining DSW with groundwater or reclaimed wastewater may successfully improve the water's irrigation qualities and reduce the risk of soil degradation.

Mendoza-Grimón et al. (2019) [10] investigated B toxicity in banana crops of Gran Canaria Island after 30 years of drip irrigation using DSW with B contents above $1.0 \mathrm{mgL}^{-1}$. Analyzing B concentration in water and soil samples at different periods, the authors established that hot water soluble boron (HWSB) in banana soils has not significantly increased during the last few decades. 
Boron balance in the banana crop indicates that approximately just $10 \%$ of the total B annually added with DSW is exported with the crop, and since low leaching fractions are applied due to the price of DSW and water scarcity, a significant soil B increase would be expected. Based on these results, the authors question the adequacy of the standard method of soil B measurement to estimate B risk in these soils. Additionally, the results do not show a progressive increase in B tissue levels and no phytotoxicity has been observed in banana orchards. The authors hypothesize that appropriate soil and water management practices, such as soil amendment (i.e., lime, gypsum, organic matter) and water blending strategies, are likely the reasons for the low B content measured in banana leaves.

\section{Conclusions}

The experiences described in this Special Issue demonstrate that DSW may be a solution for effectively removing the water constraints for irrigated agriculture in coastal regions facing persistent water scarcity. It can also foster irrigated agriculture resilience as water scarcity intensifies in a changing climate, helping to preserve socioeconomic development in highly profitable agricultural areas where no other water resources and/or economic activity alternatives are possible.

The presented trials and study cases confirm that DSW use in agriculture is limited by its high cost in comparison with other water supplies and by some agronomic concerns which need to be considered in order to avoid unexpected adverse effects. Both economic and agronomic issues highlight the benefits of the integrated planning and management of DSW and other available water resources. The proper, integrated management of DSW for irrigation should not comprise agricultural productivity or yield quality.

Author Contributions: Conceptualization, V.M.-A., A.B.-T., F.J.D.P. and J.F.M.-V.; writing, V.M.-A., A.B.-T., F.J.D.P. and J.F.M.-V. All authors have read and agreed to the published version of the manuscript.

Acknowledgments: We acknowledge all the authors that has contributed to this special issue with their research works.

Conflicts of Interest: The authors declare no conflict of interest.

\section{References}

1. Martínez-Alvarez, V.; González-Ortega, M.J.; Martín-Gorriz, B.; Soto-García, M.; Maestre Valero, J.F. The use of desalinated seawater for crop irrigation in the Segura River Basin (south-eastern Spain). Desalination 2017, 364, 2-16. [CrossRef]

2. Yermiyahu, U.; Tal, A.; Ben-Gal, A.; Bar-Tal, A.; Tarchitzky, J.; Lahav, O. Rethinking desalinated water quality and agriculture. Science 2007, 318, 920-921. [CrossRef] [PubMed]

3. Martínez-Alvarez, V.; Maestre-Valero, J.F.; González-Ortega, M.J.; Gallego-Elvira, B.; Martin-Gorriz, B. Characterization of the Agricultural Supply of Desalinated Seawater in Southeastern Spain. Water 2019, 11, 1233. [CrossRef]

4. Maestre-Valero, J.F.; Martínez-Alvarez, V.; Jódar-Conesa, F.J.; Acosta, J.A.; Martin-Gorriz, B.; Robles, J.M.; Pérez-Pérez, J.G.; Navarro, J.M. Short-Term Response of Young Mandarin Trees to Desalinated Seawater Irrigation. Water 2020, 12, 159. [CrossRef]

5. Antolinos, V.; Sánchez-Martínez, M.J.; Maestre-Valero, J.F.; López-Gómez, A.; Martínez-Hernández, G.B. Effects of Irrigation with Desalinated Seawater and Hydroponic System on Tomato Quality. Water 2020, 12, 518. [CrossRef]

6. Ricart, S.; Villar-Navascués, R.; Gil-Guirado, S.; Rico-Amorós, A.M.; Arahuetes, A. How to Close the Gap of Desalinated Seawater for Agricultural Irrigation? Confronting Attitudes between Managers and Farmers in Alicante and Murcia (Spain). Water 2020, 12, 1132. [CrossRef]

7. Russo, D.; Kurtzman, D. Using Desalinated Water for Irrigation: Its Effect on Field Scale Water Flow and Contaminant Transport under Cropped Conditions. Water 2019, 11, 687. [CrossRef] 
8. Bar-Tal, A.; Kiwonde, E.; Kanner, B.; Kurtzman, D.; Nitsan, I.; Shawahna, R. Nitrogen fertilization of plants in the desalinated-water era: A study of interactions of nitrogen with chloride. Water 2020, Submitted.

9. Monterrey-Viña, A.; Musicki-Savic, A.; Díaz-Peña, F.J.; Peñate-Suárez, B. Technical and Agronomical Assessment of the Use of Desalinated Seawater for Coastal Irrigation in an Insular Context. Water 2020, 12, 272. [CrossRef]

10. Mendoza-Grimón, V.; Fernández-Vera, J.R.; Hernández-Moreno, J.M.; Palacios-Díaz, M.P. Sustainable Irrigation Using Non-Conventional Resources: What has Happened after 30 Years Regarding Boron Phytotoxicity? Water 2019, 11, 1952. [CrossRef]

(C) 2020 by the authors. Licensee MDPI, Basel, Switzerland. This article is an open access article distributed under the terms and conditions of the Creative Commons Attribution (CC BY) license (http://creativecommons.org/licenses/by/4.0/). 